\section{Nuclear cardiology}

\section{Constantinos Anagnostopoulos, chief researcher (associate professor) in nuclear medicine; head, Research Division of Nuclear Medicine, Clinical Research Center, Biomedical Research Foundation Academy of Athens}

Richard Underwood, honorary consultant, Royal Brompton Hospital; professor of cardiac imaging National Heart \& Lung Institute, Imperial College London

Nuclear cardiology has grown significantly in recent years because of developments in imaging hardware, software and tracers. Alongside these technical developments, there has been an increasing appreciation of the role the functional information provided by nuclear techniques can play in clinical cardiology to the point of improving patient outcome. This brief review discusses the principles of nuclear cardiology and its clinical applications, emphasising the role of myocardial perfusion scintigraphy (MPS).

\section{Instrumentation}

Most nuclear cardiology studies are performed using a conventional gamma camera with a sodium iodide detector and single photon emission computed tomography (SPECT). A new generation of cameras is now available which use cadmium zinc telluride detectors and have higher sensitivity and resolution. ${ }^{1}$ There has also been increasing interest in cardiac positron emission tomography (PET). Both SPECT and PET cameras have been combined with computed X-ray tomography (CT), offering not only more accurate attenuation correction but also making possible evaluation of coronary calcification and coronary anatomy in the same sitting with myocardial perfusion. ${ }^{2}$

\section{Techniques}

\section{Assessment of myocardial perfusion}

Radiotracers. Three tracers for MPS are commercially available (Table 1):

Table 1. Common radionuclides used in myocardial perfusion scintigraphy.

\begin{tabular}{|c|c|c|}
\hline & Thallium-201 & Technetium-99m \\
\hline Perfusion tracer & Thallous chloride & MIBI and tetrofosmin \\
\hline \multirow{2}{*}{$\begin{array}{l}\text { Uptake } \\
\text { mechanism }\end{array}$} & $\mathrm{Na}+/ \mathrm{K}+\mathrm{ATPase}$ pump $(60 \%)$ & Passive diffusion \\
\hline & Passive diffusion ( $40 \%$ ) & \\
\hline Production & Cyclotron & Generator \\
\hline Photon energy & $79 \mathrm{keV}$ & $140 \mathrm{keV}$ \\
\hline Image resolution & + & ++ \\
\hline $\begin{array}{l}\text { Myocardial } \\
\text { extraction }\end{array}$ & ++ & ++ \\
\hline $\begin{array}{l}\text { Time to imaging } \\
\text { after injection }\end{array}$ & $0-5 \min$ & $\begin{array}{l}45-60 \mathrm{~min} \text { (potentially less with } \\
\text { tetrofosmin) }\end{array}$ \\
\hline Redistribution & Yes & Not clinically significant \\
\hline $\begin{array}{l}\text { Extracardiac } \\
\text { uptake }\end{array}$ & Stomach & Stomach, hepatobiliary, gut \\
\hline Half-life & 72 hours & 6 hours \\
\hline Excretion & Renal & Hepatobiliary \\
\hline $\begin{array}{l}\text { Typical radiation } \\
\text { dose }\end{array}$ & $\begin{array}{l}14 \mathrm{mSv} \text { for } 80 \mathrm{MBq} \text {, less } \\
\text { with solid state cameras } \\
\text { and resolution recovery } \\
\text { reconstruction }\end{array}$ & $\begin{array}{l}8-10 \mathrm{mSv} \text { for } 1,000 \mathrm{MBq} \text {, less with } \\
\text { solid state cameras and resolution } \\
\text { recovery reconstruction }\end{array}$ \\
\hline
\end{tabular}

- thallium-201

- technetium-99m-MIBI, and

- technetium-99m tetrofosmin.

For PET perfusion imaging, rubidium-82, which is produced by a generator, is the most commonly used tracer, but the shorter lived perfusion tracers such as oxygen-15 water and nitrogen-13 ammonia are used in centres that have an on-site cyclotron.

Stress tests (Table 2). The most commonly used technique is dynamic exercise. However, exercise may be difficult in those with limited mobility or may be contraindicated in patients with left ventricular (LV) outflow tract obstruction or left main stem coronary disease. Furthermore, certain conditions such as left bundle branch block (LBBB) and permanent pacing can be associated with stress-induced perfusion abnormalities at high heart rates in the absence of obstructive coronary artery disease (CAD). ${ }^{3}$ For such patients, pharmacological manipulation of myocardial perfusion and oxygen demand is a valuable technique and is the default method of stress for PET perfusion studies. Pharmacological stress is accomplished with adenosine or dipyridamole; dobutamine is used where vasodilators are contraindicated in patients with, for example, sinoatrial disease or persistent asthma. $^{3}$

To avoid the side effects of vasodilator stress, agonists with a high selectivity for the adenosine $A_{2 A}$ receptors responsible for the coronary vasodilator effect of adenosine have been developed. The only one commercially available is regadenoson and this has been used increasingly in the UK since $2011 .^{4}$

It is also possible to combine stress techniques, the commonest pairing being dynamic exercise up to $75 \mathrm{~W}$ with either adenosine or dipyridamole. This increases sensitivity for the detection of perfusion defects and their visibility and also reduces the vasodilator side effects.

Image interpretation. Myocardial perfusion - and hence tracer distribution - is uniform in normal myocardium (Fig 1). A defect indicates reduced perfusion in viable myocardium, reduced amount of viable myocardium or a combination of both. If a stress defect returns to normal in the resting images, this indicates the presence of an 
Table 2. Summary of stress test protocols.

\begin{tabular}{|c|c|c|c|c|c|}
\hline & Exercise & Adenosine & Dipyridamole & Regadenoso & Dobutamine \\
\hline $\begin{array}{l}\text { Mechanism } \\
\text { of action }\end{array}$ & $\begin{array}{l}\text { Secondary coronary } \\
\text { vasodilatation in response } \\
\text { to increased myocardial } \\
\text { oxygen demand. } \\
\text { Induction of true } \\
\text { ischaemia }\end{array}$ & $\begin{array}{l}\text { Primary coronary } \\
\text { vasodilatation } \\
\text { through unselective } \\
\text { adenosine receptor } \\
\text { stimulation }\end{array}$ & $\begin{array}{l}\text { Primary coronary } \\
\text { vasodilatation } \\
\text { through } \\
\text { inhibition of } \\
\text { endogenous } \\
\text { adenosine } \\
\text { reuptake }\end{array}$ & $\begin{array}{l}\text { Primary coronary } \\
\text { dilatation } \\
\text { through selective } \\
\text { adenosine } \mathrm{A}_{2 \mathrm{a}} \\
\text { receptor } \\
\text { stimulation }\end{array}$ & $\begin{array}{l}\text { Secondary coronary } \\
\text { vasodilatation through beta- } \\
\text { adrenoceptor mediated } \\
\text { increase in myocardial } \\
\text { contractility and heart rate }\end{array}$ \\
\hline Protocol & $\begin{array}{l}\text { Incremental dynamic } \\
\text { exercise }\end{array}$ & $\begin{array}{l}140 \mu \mathrm{g} / \mathrm{kg} / \mathrm{min} \text { iv } \\
\text { for } 6 \mathrm{~min}\end{array}$ & $\begin{array}{l}140 \mu \mathrm{g} / \mathrm{kg} / \mathrm{min} \text { iv } \\
\text { for } 4 \mathrm{~min}\end{array}$ & $\begin{array}{l}400 \mu \mathrm{g} \text { iv bolus } \\
\text { injection }\end{array}$ & $\begin{array}{l}\text { Incremental doses in 3-min } \\
\text { steps to } 40 \mu \mathrm{g} / \mathrm{kg} / \mathrm{min} \text { iv }\end{array}$ \\
\hline Test duration & Variable & $6 \mathrm{~min}$ & $8 \mathrm{~min}$ & $30 \mathrm{~s}$ & Variable \\
\hline $\begin{array}{l}\text { Radionuclide } \\
\text { injection time }\end{array}$ & $\begin{array}{l}\text { At peak exercise; continue } \\
\text { exercise for } 2 \text { min to allow } \\
\text { for myocardial tracer } \\
\text { extraction }\end{array}$ & $\begin{array}{l}4 \text { min after start of } \\
\text { infusion }\end{array}$ & $\begin{array}{l}4 \text { min after end } \\
\text { of infusion }\end{array}$ & $\begin{array}{l}30 \mathrm{~s} \text { after bolus } \\
\text { injection }\end{array}$ & $\begin{array}{l}\text { At } \geqslant 85 \% \text { target heart rate } \\
\text { or after } 3 \mathrm{~min} \text { at } 40 \mu \mathrm{g} / \mathrm{kg} / \\
\min \end{array}$ \\
\hline
\end{tabular}

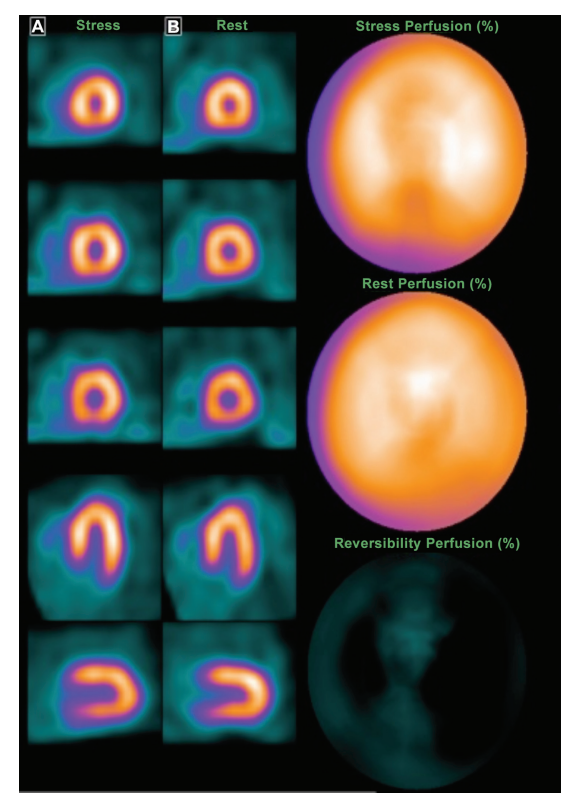

Fig 1. Normal myocardial perfusion scintigraphy using thallium-201 with three selected short axis slices and central horizontal and vertical long axis slices after stress (left) and rest (centre). All parts of the left ventricular (LV)

myocardium having high tracer uptake are shown in orange and white. The polar plots (right) show all parts of the LV myocardium in a single circular image. These can be compared with normal databases to assess the depth and extent of abnormalities and the overall ischaemic burden.

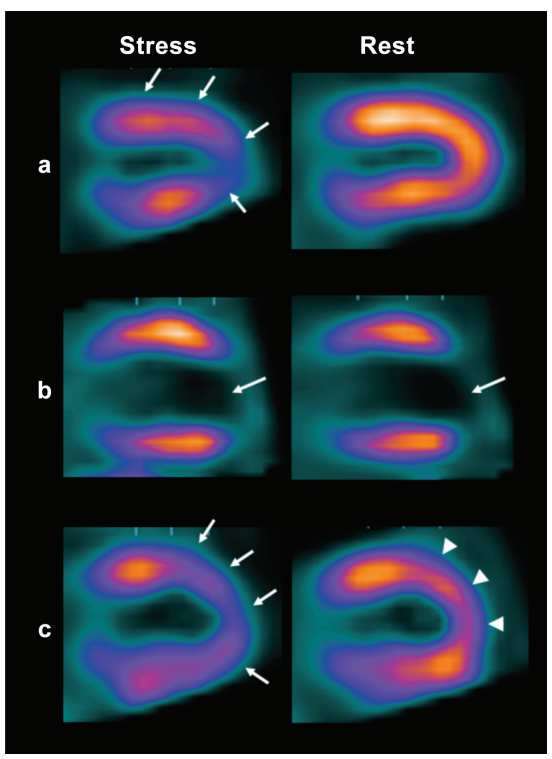

Fig 2. Patterns of myocardial perfusion shown from central vertical long axis slices. (a) Inducible perfusion abnormality without myocardial scarring. There is reduced tracer uptake on stress imaging (arrows), severe at the apex and mild in the anterior wall, which returns to normal at rest. (b) Myocardial infarction. Uptake is absent at the apex on stress images, remaining unchanged on rest imaging (arrows). (c) Partial thickness myocardial infarction with superimposed inducible ischaemia. There is moderate reduction of tracer uptake in the apex and apical anterior and inferior walls (arrows) on stress imaging. Images acquired at rest show improvement in these areas, but the anterior wall and apex fail to return to normal, indicating partial thickness myocardial damage (arrowheads). inducible perfusion abnormality. Areas of infarction show a defect in both stress and rest images and the depth of the defect indicates the amount of myocardial loss (Fig 2). Another important feature is that less marked LV dilatation in the resting stress images implies extensive inducible ischaemia and is associated with an adverse prognosis.

\section{Other nuclear cardiology techniques}

In previous decades, assessment of LV function was commonly performed by equilibrium radionuclide ventriculography (RNV) using technetium-99m labelled erythrocytes. ${ }^{5}$ For biventricular functional assessment, a first-pass technique based on the first passage of the tracer through the central circulation is well validated..$^{5}$ Both techniques have now largely been replaced by either ECG-gated SPECT of the perfusion images or echocardiography. However, SPECT blood pool imaging has some advantages, including the assessment of inter- and intraventricular synchrony from the phase image. RNV is now most commonly used for monitoring LV function in patients receiving potentially cardiotoxic chemotherapy such as doxorubicin and trastuzumab. ${ }^{5}$

An emerging tool for clinical studies is a norepinephrine analogue, iodine-123 metaiodobenzylguanidine (mIBG), which allows imaging of sympathetic myocardial innervation and provides prognostic information in patients with heart failure independently 
Table 3. High-risk imaging variables.

- Multiple myocardial perfusion defects

- Extensive reversibility of perfusion defect

- Transient LV dilatation

- Multiple regional wall motion or thickening abnormalities

- LV ejection fraction $<35 \%$

- Increased end-diastolic or end-systolic volume on ECG-gated SPECT

- Increased lung tracer uptake

$\mathrm{LV}=$ left ventricular; SPECT $=$ single photon emission computed tomography.

of other risk predictors such as LV ejection fraction and brain natriuretic peptide. ${ }^{6}$

Assessment of myocardial metabolism in combination with myocardial perfusion is a relatively common examination in heart failure patients for identification of myocardial hibernation. Glucose metabolism is most easily imaged using 2-fluoro-deoxyglucose (FDG) labelled with fluorine-18. ${ }^{7}$

\section{Clinical applications}

\section{Myocardial perfusion scintigraphy}

The National Institute for Health and Clinical Excellence recommends imaging of coronary function using, among other procedures, MPS in patients with a pretest likelihood of disease of $30-60 \%$. When CAD is already known to be present, MPS may be considered in symptomatic patients and coronary angiography should follow if significant ischaemia is present. ${ }^{8}$ All guidelines emphasise the accuracy of vasodilator stress with MPS in patients with LBBB, paced rhythm, resting ST-segment depression greater than $1 \mathrm{~mm}$ or pre-excitation. Normal stress MPS indicates the absence of functionally significant CAD. A recent meta-analysis showed sensitivity and specificity of $85-90 \%$ and $70-75 \%$, respectively, for the detection of angiographically significant CAD. ${ }^{9}$ In practice, specificity is higher than this level because some of the studies suffer from post-test referral bias.

Prognosis. Numerous studies have confirmed the excellent prognostic power of MPS, its important role in risk stratification and patient management, as well as its cost-effectiveness. A normal scan is associ-

\section{Key points}

A normal stress myocardial perfusion scintigraphy (MPS) indicates the absence of functionally significant coronary artery disease (CAD)

Sensitivity and specificity values of MPS of at least $80-90 \%$ for angiographically significant CAD

MPS for the assessment of myocardial ischaemia and scarring is an integral part of clinical guidelines and appropriateness criteria in many clinical settings

A normal MPS indicates a $\mathbf{0 . 7 \%}$ annual risk of infarction and cardiac death, similar to that of the general population. An abnormal MPS confers approximately a seven-fold increase in annual coronary events. The likelihood of an event increases with the extent and severity of the inducible perfusion abnormalities

Observational studies suggest that if more than $10 \%$ of the myocardium is ischaemic by MPS, clinical outcome is better with revascularisation than with medical therapy. The reverse is true if less than $10 \%$ is ischaemic

Positron emission tomography (PET) is an accurate standard for quantitative myocardial perfusion and viability

PET is the only modality for which randomised data exist demonstrating that patients with severe left ventricular dysfunction whose therapy is guided by fluorodeoxyglucose/PET have better outcome than with standard care

KEYWORDS: coronary artery disease, positron emission tomography (PET), single photon PET

ated with an annual risk of infarction and cardiac death of $0.7 \%$, similar to that of the general population. An abnormal scan confers around a seven-fold increase in annual coronary events. The likelihood of an event increases with the extent and severity of the inducible perfusion abnormalities. ${ }^{10}$

Asymptomatic patients. For assessment of asymptomatic patients, international guidelines support MPS if there is a family history of premature $\mathrm{CAD}$ and in patients with diabetes and abnormal resting ECG or increased calcium score. ${ }^{11}$ MPS is also appropriate for assessment of asymptomatic patients undergoing elective intermediate to high risk non-cardiac-surgery. ${ }^{12}$

The acute setting. In the acute setting, the American Heart Association recommends MPS in patients with an intermediate likelihood of CAD presenting to the emergency room with chest pain in the absence of diagnostic ECG changes. ${ }^{13}$ Normal MPS excludes infarction, so stress testing may then safely be considered to rule out inducible ischaemia. Conversely, an abnormal result has a high sensitivity for obstructive CAD leading to an acute coronary syndrome (ACS), particularly when associated with a regional wall motion abnormality.
In patients with ACS treated with coronary stenting, MPS is useful in the evaluation of the functional significance of non-culprit stenoses. After ST elevation myocardial infarction (STEMI), stable patients who have not undergone coronary angiography can be evaluated further by MPS within two to four days of infarction, contributing to risk stratification and further management plans. European and American guidelines also support the use of MPS for the detection of ischaemia in patients with non-STEMI who are not candidates for early intervention. ${ }^{14,15}$

Myocardial viability and hibernation. MPS has been used extensively in the evaluation of myocardial viability and hibernation. A large body of evidence supports current guidelines which recommend viability assessment in patients with dyspnoea and chronic ischaemic LV dysfunction. ${ }^{16}$ Uptake of more than $50 \%$ of maximum after tracer injection under nitrate cover is accepted as a marker of viability, with a minimum of four viable segments (approximately $25 \%$ of the left ventricle) needed to predict improvement of LV function after revascularisation. The most recent meta-analysis confirmed earlier data and showed that MPS is sensitive 
(83-87\%) but less specific (54-65\%) than techniques which challenge myocardial contractile reserve, such as dobutamine echocardiography and cardiac magnetic resonance $(\mathrm{CMR})$, for predicting recovery of regional function after revascularisation (sensitivity $80 \%$ for dobutamine echocardiography vs $74 \%$ for CMR; specificity $78 \%$ for dobutamine echocardiography vs $82 \%$ for CMR). ${ }^{17}$ For contrast-enhanced CMR, these values are $84 \%$ and $63 \%$.

The usefulness of MPS in this setting has been challenged recently by the substudy of the Surgical Treatment for Ischaemic Heart Failure (STICH) trial. $^{18}$ The presence of viable myocardium was associated with an increased probability of survival, but viability assessment failed to identity patients with a survival benefit from surgical revascularisation compared with medical therapy alone. The results need to be interpreted with caution because the study definition of viability included myocardial segments that were viable, but not necessarily dysfunctional, and hence not necessarily either hibernating of even ischaemic. In addition, viability assessment was performed in a non-randomised fashion in only $50 \%$ of patients, leading to the potential for significant recruitment bias.

\section{Positron emission tomography}

PET is another option for assessing myocardial perfusion and is considered the non-invasive gold standard for this indication because of its capacity to provide accurate and reproducible measures of perfusion in absolute terms $(\mathrm{ml} / \mathrm{g} / \mathrm{min})$ both at rest and stress. Its clinical utility, however, is constrained by high cost and low availability compared with SPECT.

PET has also been used for risk stratification. Its overall prognostic value has been demonstrated in several studies. In particular, measurement of coronary flow reserve offers additional prognostic information over qualitative analysis and SPECT MPS. ${ }^{19}$ PET has also been considered for many years as the gold standard for assessment of myocardial viability and hibernation using metabolic tracers. Dysfunctional myocardial segments with higher FDG uptake compared with that of ammonia or rubidium-82 (mismatch between perfusion and metabolism) represent hibernating myocardium, while reduction of both perfusion and metabolism corresponds with myocardial scar. In cases of myocardial stunning, perfusion is normal or almost normal while FDG uptake is variable.

PET is the only modality at present for which there is good quality information from a randomised study (PARR-2) demonstrating that patients with severe LV dysfunction whose therapy was guided by FDG PET have better outcome than with standard care. ${ }^{20}$

\section{Conclusions}

Nuclear cardiology techniques and MPS in particular have proven value for the diagnosis and prognosis of CAD in a safe and cost-effective way. Experience with the techniques can be measured over decades and there is a wide body of evidence to support their integration into investigative strategies for CAD.

\section{References}

1 Bocher M, Blevis IM, Tuskerman L et al. A fast cardiac gamma camera with dynamic SPECT capabilities: design, system validation and future potential. Eur J Nucl Med Mol Imaging 2010;37:1887-902.

2 Blankstein R, Di Carli MF. Integration of coronary anatomy and myocardial perfusion imaging. Review. Nat Rev Cardiol 2010;7:226-36.

3 Hesse B, Tägil K, Cuocolo A et al. EANM/ ESC procedural guidelines for myocardial perfusion imaging in nuclear cardiology. Eur J Nucl Med Mol Imaging 2005;32:855-97.

4 Thomas GS, Tammelin BR, Schiffman GL et al. Safety of regadenoson, a selective adenosine $\mathrm{A} 2 \mathrm{~A}$ agonist, in patients with chronic obstructive pulmonary disease: A randomized, double-blind, placebo-controlled trial (RegCOPD trial). J Nucl Cardiol 2008;15:319-28.

5 Hesse B, Lindhardt TB, Acampa W et al. EANM/ESC guidelines for radionuclide imaging of cardiac function. Eur J Nucl Med Mol Imaging 2008;35:851-85.

6 Perrone-Filardi P, Paolillo S, Dellegrottaglie $\mathrm{S}$ et al. Assessment of cardiac sympathetic activity by MIBG imaging in patients with heart failure: a clinical appraisal. Review. Heart 2011;97:1828-33.

7 Shellbert HR, Prior JO. Positron emission tomography. In: Fuster V, O’Rourke RA, Poole-Wilson P et al (eds). Hurst's The Heart. New York: McGraw-Hill Companies Inc, 2004:557-693.
8 National Institute for Health and Clinical Excellence. Chest pain of recent onset: assessment and diagnosis of recent onset chest pain or discomfort of suspected cardiac origin (CG95), 2010. London: NICE, 2010.

9 Loong CY, Anagnostopoulos C. Diagnosis of coronary artery disease by radionuclide myocardial perfusion imaging. Heart 2004;90(Suppl 5):v2-9.

10 Shaw LJ, Narula J. Risk assessment and predictive value of coronary artery disease testing. Review. J Nucl Med 2009;50: 1296-306.

11 Greenland P, Alpert JS, Beller GA et al. American College of Cardiology Foundation/American Heart Association Task Force on Practice Guidelines. 2010 ACCF/AHA guideline for assessment of cardiovascular risk in asymptomatic adults: a report of the American College of Cardiology Foundation/American Heart Association Task Force on Practice Guidelines. Circulation 2010;122:e584636.

12 Fleisher LA, Beckman JA, Brown KA et al. Society for Vascular Medicine and Biology. 2009 ACCF/AHA focused update on perioperative beta blockade incorporated into the ACC/AHA 2007 guidelines on perioperative cardiovascular evaluation and care for noncardiac surgery: a report of the American College of Cardiology Foundation/American Heart Association Task Force on Practice Guidelines. Circulation 2009;120:e169276.

13 Amsterdam EA, Kirk JD, Bluemke DA et al. American Heart Association Exercise, Cardiac Rehabilitation, and Prevention Committee of the Council on Clinical Cardiology, Council on Cardiovascular Nursing, and Interdisciplinary Council on Quality of Care and Outcomes Research. Testing of low-risk patients presenting to the emergency department with chest pain: a scientific statement from the American Heart Association. Circulation 2010;122:1756-76.

14 Antman EM, Anbe DT, Armstrong PW et al. ACC/AHA guidelines for the management of patients with ST-elevation myocardial infarction. A report of the American College of Cardiology/American Heart Association Task Force on Practice Guidelines (Committee to Revise the 1999 Guidelines for the Management of patients with acute myocardial infarction) $\mathrm{J} \mathrm{Am}$ Coll Cardiol 2004;44:671-719.

15 Bassand JP, Hamm CW, Ardissino D et al. Task Force for Diagnosis and Treatment of Non-ST-Segment Elevation Acute Coronary Syndromes of European Society of Cardiology. Guidelines for the diagnosis and treatment of non-ST-segment elevation acute coronary syndromes. Eur Heart $J$ 2007;28:1598-660. 
16 Wins W, Koln P, Danchin N et al. Task Force on Myocardial Revascularization of the European Society of Cardiology (ESC) and the European Association for CardioThoracic Surgery (EACTS); European Association for Percutaneous Cardiovascular Interventions (EAPC). Guidelines on myocardial revascularization. Eur Heart J 2010;31:2501-55.

17 Schinkel AF, Bax JJ, Poldermans D et al. Hibernating myocardium: diagnosis and patient outcomes. Review. Curr Probl Cardiol 2007;32:375-410.

18 Bonow RO, Maurer G, Lee KL et al. Myocardial viability and survival in ischaemic left ventricular dysfunction. $N$ Engl J Med 2011;364:1617²5.

19 Ghosh N, Rimoldi OE, Beanlands RS, Camici PG. Assessment of myocardial ischaemia and viability: role of positron emission tomography. Eur Heart J 2010;31:2984-95.

20 D’Egidio G, Nichol G, Williams KA et al. PARR-2 Investigators. Increasing benefit from revascularization is associated with increasing amounts of myocardial hibernation: a substudy of the PARR-2 trial. JACC Cardiovasc Imaging 2009;2:1060-8.

Address for correspondence: Dr C D Anagnostopoulos, Centre for Clinical and Translational Research, Biomedical Research Foundation of the Academy of Athens, 4 Soranou Ephessiou Street, 11527, Athens, Greece.

E-mail: cdanagnostopoulos@

bioacademy.gr 